\title{
Lipoprotein Lipase Gene in Red Sea Bream; A Summarized Paper
}

\author{
HIROMIOKU, XU-FANG LIANG, AND HIROSHI Y. OGATA
}

National Research Institute of Aquaculture, Nansei, Mie,516-0193,Japan (hiromi@fra.affrc.go.jp)

SUMMARY: Lipoprotein lipase (LPL) is a key enzyme of lipid metabolism. The elucidation of the structure, function and regulation of LPL is important for understanding the lipid metabolism in fish. Recently, we have cloned the LPL gene of red sea bream (Pagrus major) and characterized it by CDNA and genomic structure analysis. Subsequently, using the cloned sequence, gene expression has been investigated. We review in this report the features of red sea bream LPL gene. Red sea bream LPL gene spans 6.3kb of the genome and is organized into ten exons and nine introns. The deduced amino acid sequences showed high degree of similarities to the LPLs of other animals. In a 1.1 kb 5' flanking region, the homologous sequences for the response elements of Insulin, glucocorticoid and thyroid homone were detected. These results suggest the hormonal regulation of the LPL gene expression. Red sea bream LPL gene was expressed in various tissues including adipose tissue, heart, liver (hepatopancreas) and muscle. A fourteen-week feeding experiment was conducted to investigate the effects of feeding condition and dietary lipid level. The results suggest that LPL gene expression in visceral adipose tissue and liver is regulated in tissue-specific manner. The expression level in adipose tissue was down-regulated during starvation whereas it was up-regulated in liver. The effects of dietary lipid level on the gene expression were not observed. These results will facilitate further study on the function and regulation of the LPL in fish.

\section{KEY WORDS: Lipoprotein lipase, LPL gene, red sea bream, Pagrus major.}

\section{INTRODUCTION}

Lipoprotein lipase (LPL) plays an important role in plasma lipoprotein metabolism. LPL hydrolyzes triacylglycerols present in plasma lipoproteins and supplies free fatty acids for storage in adipose tissue, or for oxidation in other tissues. ${ }^{1)}$ Studies of mammalian and avian LPL have revealed that the LPL protein contains multiple functional domains required for secretion, glycosylation, catalysis, and lipid and heparin binding. These functional domains are highly conserved throughout evolution. ${ }^{2}$

LPL is synthesized in various tissues including adipose tissue, heart and muscle. The synthesis of LPL is regulated in response to nutritional, hormonal and developmental states of animals. Quantitative RNA analyses revealed that a part of the regulation is due to the change of the gene expression level, and that the gene expression level is mediated according to the physiological state of animals. $3,4,5,6,7,8,9)$

To understand the molecular mechanisms of lipid metabolism in fish, elucidation of structure, function and regulation of LPL are important. Biochemical approaches have been conducted on fish $L P L,{ }^{10,11,12)}$ and the cDNA sequences of zebrafish and rainbow trout LPL are available. ${ }^{13,14)}$ Recently, the red sea bream LPL gene was cloned in our laboratory and characterized by cDNA and genomic structure analyses. Using the cloned sequence, the gene expression was investigated. In this report, we review the features of red sea bream LPL gene with recent progress. Parts of this study were submitted as ref (15) and (16).

\section{STRUCTURAL FEATURE OF RED SEA BREAM LPL GENE}

The details of this section were submitted as ref (15). The $2,946 \mathrm{bp}$ of cDNA and 7,294bp of the genomic sequences of red sea bream LPL are available under the DDBJ accession number $\mathrm{AB} 054062$ and $\mathrm{AB} 054063$, respectively.

The red sea bream LPL gene spans a region of approximately $6.3 \mathrm{~kb}$ of the genome and the coding sequence is organized into ten exons and nine introns. The red sea bream LPL gene encodes 511 amino acids and the deduced amino acid sequence showed high degrees of similarity to the LPL of other animals. The amino acid sequence of red sea bream LPL exhibited 49-51\% identities to the sequences of mammalian, ${ }^{17,18,19)}$ avian ${ }^{4)}$ and rainbow trout LPL. ${ }^{14)}$

As indicated in studies in higher vertebrates, LPL contains multiple functional domains and these functional domains in LPL are postulated to be confined to specific exons $^{20211)}$ : for example, the signal peptide for secretion is assigned to exon1, the functional $\mathrm{N}$-glycosylation site to exon2, catalytic serine and a lipid binding region to exon4, a putative heparin binding region to exon6. In comparison with mammalian LPL, $2,23,24$ ) the red sea bream LPL 
showed high degrees of similarity (Fig.1). There seems to be little difference in LPL function between red sea bream and mammals.

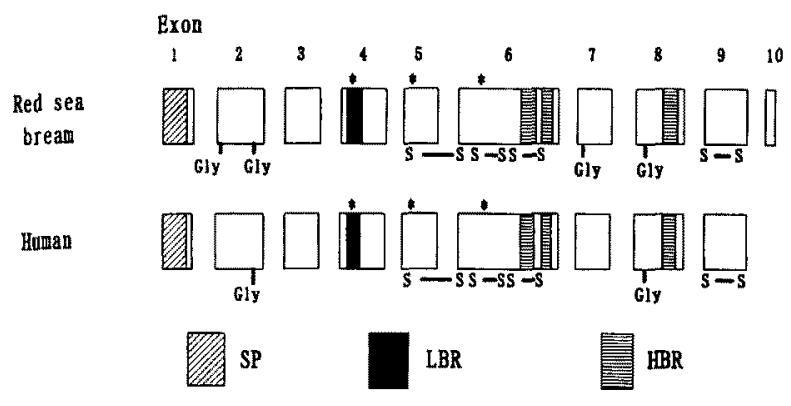

Fig. 1 Comparison of the LPL structure

SP: signal peptide, LBR: lipid binding region, HBR: heparin binding region, *: catalytic triad, Gly: potential N-glycosylation site and S-S: disulfide bond are indicated.

Within a $1.1 \mathrm{~kb}$ of the 5' flanking region, homologous sequences for potential cis-regulatory elements were detected (Fig.2). These elements were predicted by homologies to the consensus sequences reported in mammalian genes. . $^{2,26,27,28,29)}$ It remains to be determined if they are actually functional. The existence of the response elements for insulin, glucocorticoid and thyroid hormone suggests the hormonal regulation of LPL gene transcription. LPL synthesis and activation are mediated not only at transcriptional level, but also at posttranscriptional level. ${ }^{3(1)}$ To understand the regulation of LPL synthesis and activation, further analyses are required.

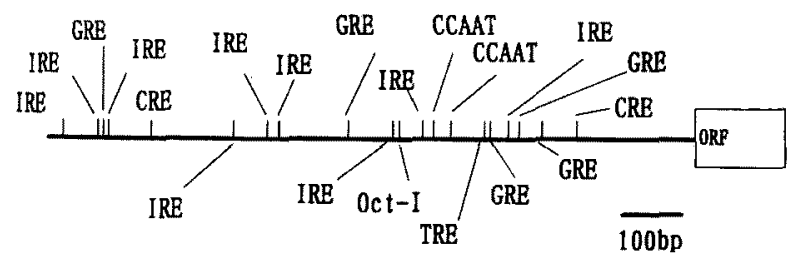

Fig. 2 Potential cis- regulatory elements in the red sea bream LPL gene 5 ' flanking region

CCAAT, Oct-I, the response elements for glucocorticoid (GRE), insulin (IRE), thyroid hormone (TRE) and cAMP (CRE) are indicated.

\section{TISSUE-SPECIFICITY OF RED SEA BREAM LPL GENE}

As mentioned in the INTRODUCTION, LPL gene is expressed in various tissues. To clarify the tissue-specificity of red sea bream LPL gene expression, the expression in visceral adipose tissue, heart, liver (hepatopancreas) and dorsal white muscle was investigated.

The total RNA was prepared from 72 $93 \mathrm{~g}$ fish, and the LPL gene expression levels were evaluated by competitive
RT-PCR method. Since the expression levels may be affected by the nutritional state in fish, the samples were prepared from fish in both fed (5hr post-feeding) and starved (48hr post feeding) conditions. However, in this experiment, the differences in the gene expression level between $5 \mathrm{hr}$ and $48 \mathrm{hr}$ post-feeding condition in each samples were not statistically significant.

Red sea bream LPL gene was expressed in all the examined tissues (Fig.3). Relatively higher levels of expression were observed in liver (48hr post-feeding) and adipose tissue (5hr post-feeding).

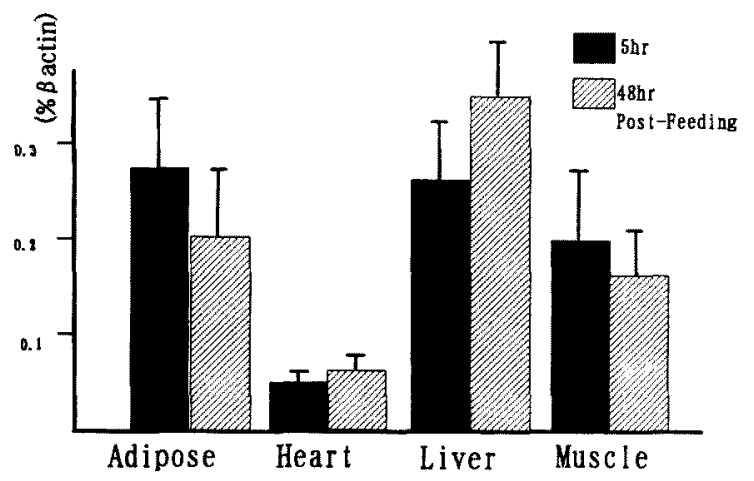

Fig 3 Tissue-specificity of the red sea bream LPL gene expression The gene expression levels (mean \pm S.E.) are indicated as $\% \beta$ actin. $(n=4)$

\section{NUTRITIONAL REGULATION OF THE GENE EXPRESSION}

The LPL gene is regulated in response to nutritional state of animals. To investigate the effects of feeding condition and dietary lipid level, a 14-week feeding experiment was conducted. The LPL gene expression levels were compared between fed (5hr post feeding) and starved (48hr post-feeding) conditions, and between the control diet fed fish (LL: dietary lipid level 15.3\%) and high lipid diet fed fish (HL: 24.6\%) (Fig.4). In this study, we estimated the gene expression level in visceral adipose tissue and liver because these tissues are major sites of lipid deposition in fish. ${ }^{31,32)}$ For the most part, this section was submitted as ref (16).

In comparison between the different feeding conditions ( $L L$; fed and starved), in the adipose tissue, the expression level under starved condition was 6.2 fold lower than that of fed condition. The LPL gene expression in the adipose tissue was down-regulated during starvation. In the liver, the LPL gene expression seems to be up-regulated during starvation. The gene expression level in the liver under starved condition was 18.3 fold higher than that of fed condition. These results suggest the gene expression in adipose tissue and liver were regulated differently in a 
tissue-specific and reciprocal manner during nutritional transition.

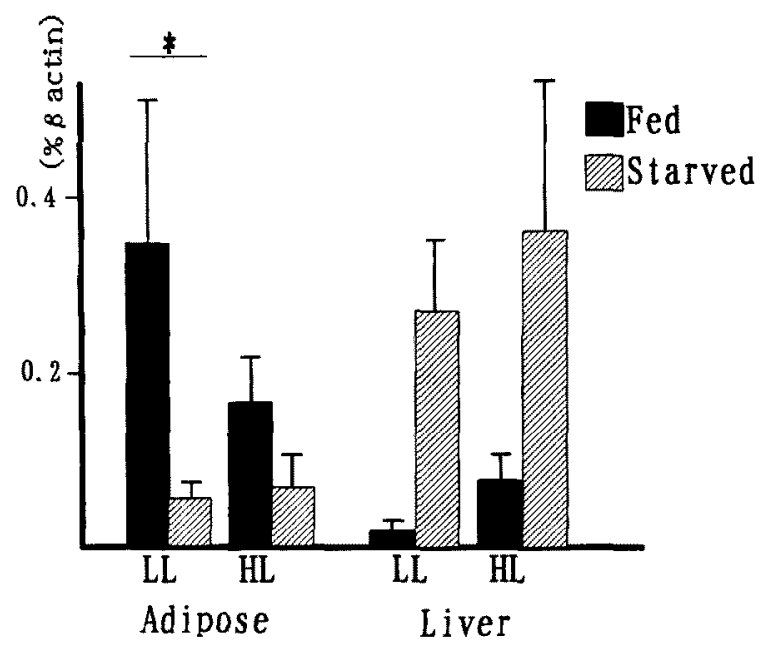

Fig. 4 Nutritional regulation of the red sea bream LPL gene expression LL: low lipid (dietary lipid level: 15.3\%), HL: high lipid (24.6\%), *: significant difference $(\mathrm{P}<0.05)$

The gene expression levels (mean \pm S.E.) are indicated as \% $\beta$ actin. $(n=4 \sim 6)$

Our research group is interested in lipid metabolism and body lipid deposition in fish with reference to fat deposition in cultured fish. As reported previously, the dietary lipid level affects the body lipid deposition. ${ }^{33)}$ In this study, to investigate the effects of dietary lipid level on the lipid metabolism, the LPL gene expression level was compared between in the control diet fed fish (LL) and high lipid diet fed fish (HL).

In comparison with the control diet fed fish (LL), any significant differences in the gene expression were not indicated in high lipid-fed fish (HL) (Fig.4). However, the LPL gene expression levels in the adipose tissue and the liver seems to be affected in response to the dietary lipid level; Under the fed condition, the LPL gene expression in the adipose tissue of the HL-fish was more than 2 fold lower than that of the LL-fish. Furthermore, the expression level in liver of HL-fish was higher than that of the LL-fish under the both fed and starved condition. (5.3 fold in fed and 1.4 fold in starved condition, respectively). To confirm the effects of dietary lipid level on lipid metabolism in fish, further studies are required.

\section{DISCUSSION}

Lipoprotein lipase belongs to the lipase gene family which includes hepatic and pancreatic lipase. These three lipases had diverged from a single ancestral gene throughout evolution, and share high degree of similarities each other. ${ }^{21,23)}$ We identified the lipase gene described in this report as LPL by the sequence homologies to the LPL of other animals and the phylogenetic analysis (data not shown). With respects to the deduced amino acid sequence, the genomic organization, and the response of the gene expression in adipose tissue during starvation, red sea bream LPL showed similar characters to the mammalian LPL.

In this study, we investigated the structure and the gene expression of red sea bream LPL gene. Our results will facilitate further study of the function and regulation of the LPL in fish. In lipid metabolism, not only LPL but other lipases are involved. For better understanding of lipid metabolism in fish, other lipases, including hepatic and pancreatic lipase should be investigated.

\section{ACKNOWLEDGMENTS}

The present research was financially supported by BioDesign program, Ministry of Agriculture, Forestry and Fisheries of Japan (BDP-01-IV-1-9). We appreciate Dr. Tohru Suzuki, Mrs. Izumi Okai (Natl. Res. Inst. of Aquaculture, Nansei, Mie, Japan) and Dr. Jeffery Silverstein (Catfish Genetic Research Unit, USDA, MS, USA) for their helpful assistance. 


\section{REFERENCES}

1. Nilson-Ehle, P., Garfinkel, A. S. and Schotz, M. C. Lypolytic enzymes and plasma lipoprotein metabolism. Ann. Rev. Biochem. 1980; 49: 667-693

2. Raisonnier, A., Etienne, J., Amault, F., Brault, D., Noe, L., Chuat, J.C. and Galibert, F. Comparison of the CDNA and amino acid sequences of lipoprotein lipase in eight species. Comp. Biochem. Physiol. 1995; 111B: $385-398$

3. Enerback, S., Semb, H., Tavernier, J., Bjursell, G. and Olivecrona, T. Tissue-specific regulation of guinea pig lipoprotein lipase; effects of nutritional state and of tumor necrosis factor on mRNA levels in adipose tissue, heart and liver. Gene 1988; 64:97-106

4. Cooper, D. A., Stein, J. C., Strieleman, P. J. and Bensadoun, A. Avian adipose lipoprotein lipase: cDNA sequence and reciprocal regulation of mRNA levels in adipose and heart. Biochim. Biophysic. Acta 1989; 1008: 92-101

5. Tavangar, K., Murata, Y., Patel, S., Kalynyak, J. E., Pedersen, M. E. Goers, J. F., Hoffman, A. R. and Kraemer, F. B. Developmental regulation of lipoprotein lipase in rats. Am. $J$. Physiol. 1992; E330-E337

6. Semenkovich, C. F., Chen, S., Wims, M., Luo, C. , L, W. and Chan, L L Lipoprotein lipase and hepatic lipase mRNA tissue specific expression, developmental regulation and evolution. $J$. Lipid Res. 1989; 30: 423-431

7. Semb, H. and Olivecrona, T. Two different mechanisms are involved in nutritional regulation of lipoprotein lipase in guinea-pig adipose tissue. Biochem. J. 1989; 262: 505-511

8. Strieleman, P. J. and Bensadoun, A. Cell-free translation of avian adipose tissue lipoprotein lipase messenger RNA Biochim Biophysic. Acta 1987; 908: 268-274

9. Lee, J., Smith, P. J. and Fried, S. K. Mechanisms of decreased lipoprotein lipase activity in adipocytes of starved rats depend on duration of starvation. J. Nutr. 1998; 128: 940-946

10. Sheridan, M. A and Allen, W. V. Partial purification of a triacylglycerol lipase isolated from steelhead trout (Salmo gairdneri) adipose tissue. Lipids 1984; 19: 347-352

11. Skinner, E. R and Youssef, A. M. The characterization of lipoprotein lipase isolated from the post-heparin plasma of the rainbow trout, Salmo gairdneri Richardson. Biochem. J. 1982; 203: $727-734$

12. Lindberg, A. and Olivecrona, G. Lipase evolution: trout, xenopus and chicken have lipoprotein lipase and apolipoprotein C-II-like activity but lack hepatic lipase-like activity. Biochim. Biophysic. Acta 1995; 1255: 205-211

13. Amault, F., Etienne, J., Noe, L., Laisonnier, A, Brault, D., Hamey, J. W., Berry, M. J., Tse, C., Fromental-Ramain, C., Hamelin, J. and Galibert, F. Human lipoprotein lipase last exon is not translated, in contrast to lower vertebrates. J. MoL Evol. 1996; 43: $109-115$

14. Lindberg, A and Olivecrona, G. Direct submission to Genbank/ EMBL, accession number AJ224693

15. Oku, H., Liang, X. F. and Ogata, H.Y. Organization of the lipoprotein lipase gene of red sea bream Pagrus major. Comp.Biochem Physiol. 2001, submitted.

16. Liang, X. F, Oku, H. and Ogata, H. Y. The effects of feeding condition and dietary lipid level on lipoprotein lipase gene expression in liver and visceral adipose tissue of red sea bream Pagrus major. Comp. Biochem. Physiol. 2001, submitted.

17. Wion, K., Kirchgessner, T. G., Lusis, A. J., Schotz, M. C. and Lawn, R. M. Human lipoprotein lipase complementary DNA sequence. Science 1987; 235: 1638-1641
18. Zechner, R., Newman, T.C., Steiner, E. and Breslow, J. L. The structure of the mouse lipoprotein lipase gene: a B1 repetitive element is inserted into the 3 ' untranslated region of the mRNA. Genomics 1991; 11: $62-76$

19. Enerback, S., Semb, H., Bengtsson-Olivecrona, G., Carlsson, P., Hermansson, M. J., Olivecrona, T. and Bjursell, G. Molecular cloning and sequence analysis of cDNA encoding lipoprotein lipase of guinea pig. Gene 1987; 58: 1-12

20. Auwerx, J., Leroy, P. and Schoonjans, K Lipoprotein lipase; Recent contributions from molecular biology. Crit. Rev. Clinic. Lab. Sci. 1992; 29: 243-268

21. Hide, W. A., Chan, L. and Li, W. H. Structure and evolution of the lipase superfamily. J. Lipid Res. 1992; 33: 167-178

22. Deeb, S. S. and Peng, R. Structure of the human lipoprotein lipase gene. Biochemistry 1989; 28: 4132-4135

23. Kirchgessner, T. D., Chuat, J. C., Heinzmann, C., Etienne, J., Guilhot, S., Svenson, K., Ameis, D., Pilon, C., d'Auriol, L., Andalibi, A., Schotz, M. C., Galibert, F.and Lusis, A. L. Organization of the human lipoprotein lipase gene and evolution of the lipase gene family., Proc. Natl. Acad. Sci. USA. 1989; 86: 9647-9651

24. Enerback, S. and Bjursell, G. Genomic organization of the region encoding guinea pig lipoprotein lipase; evidence for exon fusion and unconventional splicing. Gene 1989; 84: 391-397

25. Scheidereit, C., Geisse, S., Westphal, H. M. and Beato, M. The glucocorticoid receptor binds to defined nucleotide sequences near the promoter of mouse mammary tumor virus. Nature 1983; 304: 749-752

26. Scheidereit, C. and Beato, M. Contact between hormone receptor and DNA double helix within regulatory element of mouse mammary tumor vinus. Pro. Natl. Acad. Sci. USA. 1984; 81: 3029-3033

27. Montminy, M. R., Sevarino, K. A., Wagner, J. A., Mandel, G. and Goodman, R. H. Identification of a cyclic-AMP-responsive element within the rat somatostatin gene. Proc. Natl. Acad. Sci. USA. 1986; 83: 6682-6686

28. Flink, I. L and Morkin, E. Interaction of thyroid hormone receptors with strong and weak cis-acting elements in the human a-myosin heavy chain gene promoter. J. Biol. Chem. 1990; 265: 11233-11237

29. O'Brien, R. M. and Granner, D. K. Regulation of gene expression by insulin. Physiological review 1996; 76: 1109-1161

30. Semenkovich, C. F., Wims, M., Noe, L., Etienne, J. and Chan, L. Insulin regulation of lipoprotein lipase activity in 3T3-L1 adipocytes is mediated at posttranscriptional and posttranslational levels. J. Biol Chem. 1989; 264: 9093-9038

31. Ando, S., Mori, Y. and Nakamura, K. Characteristics of lipid accumulation types in five species of fish. Nippon Suisan Gakkaishi 1993; 59: 1559-1564

32. Zhou, S., Ackman, R. G. and Morrison, C. Adipocytes and lipid distribution in the muscle tissue of atlantic salmon (Salmo salar). Can. J. Fish Aquat. Sci. 1996; 53: 326-332

33. Oku, H. and Ogata, H. Body lipid deposition in juveniles of red sea bream (Pagrus major), yellowtail (Seriola quinqueradiata) and Japanese flounder (Paralichthys olivaceus). Fisheries Sci. $2000 ; 66: 25-31$ 